\title{
LA VISIÓN DE SAN PABLO
}

\author{
José Fradejas Lebrero.
}

UNED.

En Burgos, hacia 1493, se publicó la Infantia salvatoris, que plantea algunos problemas tanto de contenido como de atribución y de autoria.

Por el título, se pensaría en una traducción de los Evangelios Apócrifos ${ }^{1}$, pero como se atribuye a San Bernardo, abad de Caravaca, santo inexistente, a García Rojo y Ortiz de Montalván ${ }^{2}$ se les ocurrió pensar si no habría una errata por San Bernardo de Claraval y, ya en plan de hipótesis, ¿no podría ser identificado con el De Iesu puero, falsamente atribuido al santo cisterciense?

Se dice en el título: "Trata desde el nascimiento de Nuestra Señora fasta que subió a los cielos", y asi comienza el libro con el Nacimiento, Presentación y Desposorios de la Virgen (Capitulos I-III) y termina con el Tránsito de Maria a los cielos (Cap. XXXII). Parece, pues, una obra mariológica $y$, sin embargo, es una obra cristológica porque desde el Capítulo IV, sobre el Nacimiento de Cristo, hasta el XXI, sobre el Pentecostés, leemos una narración de la Vida pública - y no sólo de la Infancia - de Jesús en la cual da lugar a numerosas y efusivas meditaciones.

Se nos ocurre pensar que es una libérrima adaptación de las Meditationes vitae Christi ${ }^{3}$, atribuidas durante el siglo $\mathrm{xv}$ al Pseudo Buenaventura, ya que, en una superficial comparación, los Capitulos IV-IX se corresponden en ambas obras y también el XI-XV de la Infancia con el XII-XVII de las Meditaciones, y XXV-XXVIII con el LXXI-LXXIV de las Meditationes $\mathrm{y}$ lo mismo XXIX con LXXVIII, XXX con XCIV y XXXI con XCV.

1 A. de Santos Otero, Los Evangelios Apócrifos, Madrid, BAC, 1963², págs. 259275 y 366-372.

2 Catálogo de incunables de la Biblioteca Nacional, Madrid, 1945.

3 F. García Graviotto, Catálogo de Incunables en Bibliotecas Españolas, Madrid, Ministerio de Cultura, 1988. Las meditaciones figuran del núm. 1.257 al 1.264. Yo he manejado la edición de París [c. 1495], de la B. N. de Madrid. 
Por otro lado, ambos utilizan los Evangelios Apócrifos, de los cual en la Infancia son estupendos ejemplos el Capitulo III y el XXXII que, por cierto, no figura en las Meditationes, y en algún momento mencionan el Evangelio de Nicodemo. No son, pues, obras teológicas, sino de puro entretenimiento y de exaltación fervorosa en la cual se hace hincapié en las comparaciones y meditaciones.

Pero es que, además, este librito contiene una brevísima colección de Milagros marianos, 11 en total (fols. LVI-LxI):

Porque los miraglos suelen comover a los omes a deuoción son scriptos en un libro dicho Flos Sanctorum, e las fiestas de Sancta Maria e cuéntase así (4) :

La primera ocurrencia fue pensar en la Lcyenda Aurea de Jacobo de Vorágine, bien en una de las múltiples ediciones latinas incunables ${ }^{4} \mathrm{o}$ en alguna de las versiones o traducciones (Barcelona Rodenbach 1494 en la B. N.).

Pero hube de desechar las ediciones latinas porque los milagros VI y VII sobre Santa Leocadia y San Ildefonso, respectivamente, no aparecen en ellas. Tuve que pensar en una mera traducción y, entre las que conozco, solo introduce los santos españoles la de fray Gonzalo de Ocaña; así pues, seguramente de esta obra debió tomar estos dos milagros, pero, además, incluye el milagro IX, que es el número XVII de los Milagros de Santiago, que tampoco figura en Vorágine y sí en Ocaña.

Finalmente, y como colofón, incluye un Sermón que no es más que una versión hispana - medieval- abreviada de la apócrifa Visión de San Pablo de las penas del infierno, folios Lxinr-LXIVv.

Es un texto apócrifo, aunque ortodoxo, que se dice haber sido descubierto en Tarso, oculto en los cimientos de la casa de Pablo, durante el reinado de Teodosio (379-395) y enviado por el Emperador a Jerusalén. El Apóstol, guiado por el Archángel San Miguel, visita la mansión de los elegidos, la de los réprobos y, por último, el paraíso terrestre.

En el siglo IV, pues, existian ya, al menos, dos redacciones griegas, que no conocemos más que por testimonios de Epifanio y Agustín. Si conocemos un texto griego (Redacción I) y otro sirio (Redacción II) derivado de una versión griega mejor y más completa. Esta visión se tradujo al latín (Redacción III).

Pero el texto primitivo sufrió pronto una abreviación (Redacción IV), referida sola y exclusivamente a la visita a los infiernos, que se conserva en múltiples manuscritos y se ha llamado cuarta redacción y tiene el aspecto y la forma de un sermón. De ella han nacido todas o casi todas las versiones vulgares.

\footnotetext{
4 F. Garc|a Graviotto, Catálogo, núms. 3,083-3.103.
} 
En España hay cuatro versiones; dos latinas:

1. Siglo xil, Códice 28 de la Catedral de Barcelona, edición y estudio de Olivera ${ }^{5}$. Versión muy abreviada e incompleta, sin embargo en bastantes párrafos está muy ampliada: El comienzo sobre el río.

2. Liber infernalis, siglo xiv, Códice 204 (fol. 103) del Archivo de la Corona de Aragón en Barcelona. Estudiado por Olivar ${ }^{6}$.

3. Revelación de San Pablo, Sevilla. Menardo Ungut y Stanislao Polono, 1494. Es un tomo en $4 .^{\circ}$ de 74 hojas. Tiene XLI capítulos, este último, que es el que he leido, "fabla de como se partieron el ángel y él". El único ejemplar conocido pertenecía al Sr. Aguiló y Fuster y hoy, al parecer, para en la Biblioteca Nacional de Paris.

Fue traducido al valenciano en 1495 (B. N. P., Res. D. 9598) y hay una reedición de Toledo 1525 (BNP - Res. R - 1673-1676).

Libro curioso pero que no parece coincidir con El Apocalipsis de Paulo o Visión ya que, por el prólogo y el índice que da Secret ${ }^{7}$, más bien parece una novelización de las más antiguas versiones que no coinciden, en general, con el siguiente; nuestra desconocida versión.

4. Comienza el Sermón.

$\mathrm{Al}$ editar este texto, vamos a incluir aquellas frases o párrafos latinos de la redacción latina IV según la edición de $\mathrm{P}$. Meyer, en Romania, XXIV (1895), 365-375, y de esta manera se verán las relaciones.

No hay duda de que la Revelación, ora el Sermón, ora la edición de 1494, tuvo cierta notoriedad porque en los indices inquisitoriales de 1559, 1583 y 1612 fue prohibido. Además, y todavia en 1707, se prohibia la obra de Juan del Espino, Sobre la prophecía y palabras de San Pablo ${ }^{8}$. También fue prohibida en Portugal, en el Rol de 1547 figuraba $A$ Revelaçao de Sam Pablo; en el de 1551 aparece bajo el título latino Revelationes Sancti Pauli, in vulgari hispanico; finalmente, aparece también en el Rol de 1564: Revelaciones de S. Paulo?.

No nos preocupamos de las ligeras amplificaciones, pero si queremos reseñar algunos errores de traducción, si no es que figuraba así en el manuscrito original :

5 Scriptorium, 1946, págs. 240-242.

6 Sacris Erudiri, 1967-1968, págs. 550-554.

7 Sefarad, 1968, XXVIII, págs. 45-67.

8 A. Vilchez Díaz, Autores anónimos españoles en las Indias inquisitoriales, Madrid, U. C., 1986, núm. 1.310, pág. 92, y núm. 540, pág. 53.

- Paul Rego, Os indices expurgatorios e a cultura portuguesa, Lisboa, 1982, Biblioteca Breve, núm. 61 , págs. 42,45 y 57. 
vestiduras blancas - vestimenta nigra

siete - III ${ }^{\text {or }}$

la ora postrimera del - at hora nona sabati usque in prima hora

sábado fasta la postrimera del lunes - secunda ferie (es decir, la primera de la mañana del lunes) ${ }^{10}$

un dia e dos noches - unius diei et noctis.

Hagamos constar también la traducción de

feneratores por renoveros

y la creación de infernados, es decir, condenados en el infierno. Finalmente, la nota 18 debería ir, según el texto latino, entre 14 y 16.

\section{COMIENÇA EL SERMON}

Señores saber deuéys qual fue el que ¿ rogó primeramente que las ánimas ouiesen refrigerio en las penas del Infierno. Dízese que sant Pablo e sant Miguel archángel baxaron en el Infierno e quiso Nuestro Señor que sant Pablo supiese las penas por orden e embió a sant Miguel con él quel mostrase las penas.

$\mathrm{E}$ vio sant Pablo que eran ante las puertas del Infierno árboles de fuego e los peccadores colgados de los árboles, los vnos de los pies, e los otros por las manos, e los otros por las lenguas ${ }^{11}$.

$\mathrm{E}$ vio sant Pablo vn forno de fuego, e salían dende siete llamas e cada vna dellas de su color ${ }^{12}$ e eran ý en derredor del forno siete plagas: La primera de fuego, la segunda de elada, la tercera de nieue, la quarta de sangre, la quinta de serpientes, la sesta de rrelámpagos, la séptima de hedor.

$E$ en aquel forno son metidos ${ }^{13}$ los pecadores que no tomaron peniten$\mathrm{cia}^{14}$ en este mundo de sus peccados. Alli son las ánimas atormentadas e rresciben penas según / 63v que cada vna meresció. Las vnas llorando e las otras dando gritos, las otras gimiendo, las otras arden e demandan muerte e non la pueden auer ${ }^{15}$.

10 Es posible que haya un recuerdo de esto en la Disputa del alma y el cuerpo (v. $\left.3^{\circ}\right)$ : "Un sábado exient Doming amanezient."

11 alii capillis, alii auribus, alii brachiis.

12 et puniebantur in ea peccatrices anime.

is anime.

14 post.

15 quia anime non possunt mori. 
Señores sant Pablo nos dize que deuemos temer mucho el lugar del Infierno ${ }^{16}$ que es grand abondamiento de lágrimas ${ }^{17}$ por el mal e tormento de las ánimas.

$\mathrm{E}$ después vio sant Pablo un rrío ${ }^{18}$ correr en que eran muchos diablos así como peces en vna mar e tragauan las ánimas pecadoras sin ninguna misericordia ${ }^{19}$.

E sobre aquel rrio es vna puente por do pasauan las ánimas justas e peccadoras cada vna a su merescimiento. alli son ${ }^{20}$ las mansiones malas aparejadas asi como dize el Euangelio: Allegadvos peccadores e fazed fazes dellos ${ }^{21}$ para quemar rrapazes con rrapazes ${ }^{2}$, rrobadores con rrobadores, crueles con crueles, tanto que pueda cada vna por la puente pasar quanto ha merescido por su obra.

$\mathrm{E}$ vio sant Pablo muchas ánimas somidas las unas hasta las sobrecejas, e las otras hasta las bocas, e las otras fasta el ombligo, las otras fasta los hinojos e cada día lloran durablemente e son ator /64. mentadas, e preguntó sant Pablo que quién eran ${ }^{23}$. E dixo el ángel:

- Los que hasta el ombligo están son los que fizieron adulterios e después no se rrecordaron por penitencia. E los que fasta la boca son los que fazen las barajas en la iglesia e no oyeron las palabras de Dios. Los que fasta las sobrecejas son los traydores ${ }^{24}$.

E después vino sant Pablo a vn lugar tenebroso lleno de mugeres e de varones ${ }^{25}$ e eran en aquel lugar moças negras con vestiduras blancas e tenían alderredor de sus cuellos pez y piedra sufre, e dragones e sierpes e biuoras ${ }^{26}$. $\mathrm{E}$ preguntó sant Pablo que quién eran aquellas e dixo el ángel:

-Aquestas son las que no guardaron castidad ${ }^{27}$ e sus fijos mataron e diéronlos a comer a canes e a puercos e echáronlos en rríos e no hizieron penitencia.

E después vio sant Pablo vn lugar escuro e lleno de mugeres e de varones que comían sus lenguas e preguntó quién eran, e dixo el ángel:

\footnotetext{
16 in quo est tristicia sine leticia; in quo est dolor sempiternus; in quo est gemitus cordis.

17 cruciatio animarum; in quo est rota ignea habens mille orbitas, mille vicibus in uno die ab angelo tartareo percussa, et in unaquaque vice mille anime cruciantur.

18 horribile.

19 quasi lupi devorant oves.

20 multe bestie diabolice multeque.

21 id est similes cum similibus, adulteros cum adulteris.

22 iniquos cum iniquis.

23 Et flevit Paulus et suspiravit, interrogans angelum qui essent dimersi usque ad genua. Cui angelus dixit: "Hi sunt qui se mittunt in sermonibus alienis, [alios] detrahentes."

24 Et flevit Paulus et dixit: "Ve his quibus preparantur tante pene!"

25 comedentibus linguas suas, de quibus ait angelus: " $\mathrm{Hi}$ sunt feneratores pecuniarum qui usuras querunt et non sunt misericordes ; propterea sunt in pena."

28 Et vidit alium locum in quo omnes pene erant. ... Et quatuor angeli maligni increpantes eas, habentes cornua ignita, qui ibant in circuitu earum dicentes: "Agnoscite filium Dei qui mundum redemit."

27 usque ad nuptias.
} 
-Estos son los rrenoueros que tomauan logro e no son miericordiosos ${ }^{28}$.

$E$ después vio sant Pablo vn viejo entre siete diablos lloran /64b do e preguntó quién era, e dixo el ángel:

- Vn obispo que fue menospreciador de la ley del Saluador e luxurioso e no casto del su cuerpo ${ }^{2}$. E por ende padesce aquestas penas fasta el día del juyzio.

E lloró sant Pablo e sospiró e dixole el ángel: fierno.

- ¿ Por qué lloras Pablo? ca no has visto avn las mayores penas del In-

E mostróle vn pozo sellado con siete sellos e dixo el ángel:

-Está alexos que puedas sofrir el fedor e abrió el pozo e salió dende vn fedor malo ${ }^{30}$.

E dixo el ángel :

- Creerás que así como lo fiziere el omen así lo rrescibirá.

E dixo sant Pablo:

-¿Quáles serán los que serán metidos en este pozo?

E dixo el ángel:

- Los que no creyeron en Ihesú Christo que vino a tomar carne e nasció de sancta María, Virgen ${ }^{31}$.

$\mathrm{E}$ después ${ }^{32}$ vio sant Pablo vna ánima pecadora entre siete diablos 1lorando e gimiendo e dando gritos que traýan echándola acá e allá cada vno a la parte que queria, e asi la traýan entre sí muy maltractada. Ca la auian tomado ese dia del su cuerpo. E dixeron los ángeles que lo vieron desde el cielo :

- Crueles, malos e peruersos veamos /64v esta ánima como la lleuáys.

E rrespondieron los diablos:

-Porque despreció los mandamientos del criador en la tierra.

E dixeron:

-Ven ánima que vienes de la tierra e ley tu carta.

E el ánima leyó su carta en que falló todos sus peccaclos escriptos, e juzgóse ella mesma e los diablos tomáronla e leuáronla al Infierno.

E luego en esa ora troxieron los ángeles vn ánima justa del cuerpo e leuáronla a Parayso e oyó sant Pablo vn millón de ángeles celestiales laudando y diziendo: Criador.

-O alegre ánima e bienauenturada que feziste los mandamientos del

E ella leyó su carta en que auía escriptas sus buenas obras, e sant Miguel

28 Post hec vidit viros ac mulieres in loco glaciali, et ignis urebat de media parte et de media frigebat. Hi erant qui orphanis et viduis nocuerunt. Post hec vidit viros ac mulieres super canalia amnis, et fructus ante illos erant, quibus non licebat aliquid sumere ex eis. Et hi erant qui solverunt, jejunium ante tempus.

29 vel de verbo nec de cogitatione vel opere, sed fuit avarus et dolosus atque superbus.

30 et durus, superans omnes penas inferni.

31 et non baptizati sunt nec communicati corpore et sanguine Christi. Et vidit in alio loco viros ac mulieres, et vermes et serpentes comedentes eos. Et erat anima una super alteram quasi oves in ovili, et erat profunditas ejus quasi de terra ad celum, et audivit gemitum et suspirium magnum quasi tonitruum.

32 aspexit in celo et in terra. 
metióla en Parayso e llamaron todos los que eran en las penas del Infierno e dixeron:

- Misericordia nos faz, sant Miguel archángel.

E dixo el ángel rrogad a sant Pablo que es combusco que por las sus oraciones vos dé el Saluador algund rrefrigerio.

$\mathrm{E}$ quando aquesto oyeron todos los que estauan en las penas dixeron: -O tú, Paulo, faznos misercordia.

E sant Pablo rrogó por ellos e luego fue oydo su rruego sobre los quatro cielos. E vio sant Pablo los cielos /64 vo mouer e a Ihesu Christo decender. E dixo nuestro Señor Ihesu Christo a los infernados:

- O malditos, yo fuy por vos puesto(s) en cruz e ferido con lança ${ }^{33} \mathrm{e}$ vos fuistes malinados, soberuios e luxuriosas $\mathrm{e}^{34}$ avarientos. $\mathrm{O}$ malditos, que ningund bien fezistes sino todo $\mathrm{mal}^{35}$.

E díxoles más:

Por sant Miguel, e por los ángeles, e por Paulo, que es conbusco, e más por la mi bondad dovos refrigerio de la ora postrimera del sábado fasta la postrimera ${ }^{36}$ del lunes.

E ellos dixeron todos a vna boz bendito seas Padre, que nos diste rrefrigerio vn dia e dos noches ${ }^{37}$.

E preguntó sant Pablo quantas eran las penas del Infierno. El ángel rrespondió ciento e quarenta e quatro mill son las mayores. E las menores, si fuessen cient varones e cada vno dellos touiesen lenguas de fierro e no fuese su vida otra sino contar las penas, tantas son que antes serían escomidas que no contasen las menores penas del Infierno.

$\mathrm{E}$ nos, señores, que oymos estos males conuertirnos deuemos al Criador que rreynemos con El en rreyno perdurable. Amén.

Finis.

\footnotetext{
3s clavis confixus, acetum cum felle mixtum dedistis mihi ad portandum. Ego pro vobis memet ipsum in martirium dedi ut vinceretis mecum.

34 fures et avari et invidiosi.

35 nec ullum bonum egistis nec penitentiam nec jejunium nec elemosinam, sed mendaces fuistis in vita vestra.

* ab hora nona sabati usque in prima hora secunde ferie.

37 diei et noctis. Ideo, qui custodierint ipsum diem.
} 